Article

\title{
Beyond Interpersonal Competence: Teaching and Learning Professional Skills in Sustainability
}

\author{
Katja Brundiers * and Arnim Wiek \\ School of Sustainability, Arizona State University, P.O. Box 875502, Tempe, AZ 85287-5502, USA; \\ arnim.wiek@asu.edu \\ * Correspondence: katja.brundiers@asu.edu \\ Academic Editor: Michael Brody \\ Received: 4 January 2017; Accepted: 2 March 2017; Published: 7 March 2017
}

\begin{abstract}
Successful careers in sustainability are determined by positive real-world change towards sustainability. This success depends heavily on professional skills in effective and compassionate communication, collaborative teamwork, or impactful stakeholder engagement, among others. These professional skills extend beyond content knowledge and methodical expertise. Current sustainability programs do not sufficiently facilitate students' acquisition of such skills. This article presents a brief summary of professional skills, synthesized from the literature, and why they are relevant for sustainability professionals. Second, it presents how these skills have been taught in an undergraduate course in sustainability at Arizona State University, USA. Third, it critically discusses the effectiveness and challenges of that exemplary course. Finally, the article concludes with outlining the lessons learned that should be incorporated into future course offerings.
\end{abstract}

Keywords: sustainability; professional skills; pedagogy

\section{Introduction}

Sustainability programs in higher education often do not sufficiently prepare students for sustainability jobs in governments, NGOs, or businesses [1]. These jobs call for general professional skills to leverage specific content knowledge and methodical expertise. The literature on sustainability education has responded to these calls by including interpersonal competence, i.e., the ability to work well in teams and with a range of stakeholders, into the set of key competencies in sustainability [2]. While interpersonal competence is of relevance to sustainability professionals, the range of competitive professional skills is even broader, also including effective and compassionate communication, responsive project management, advanced continuous learning, and preventative self-care.

The demand for these skills becomes increasingly explicit in the job market (e.g., [3]). Moreover, compassion, empathy, gratitude, mindfulness, and other positive behaviors result in higher levels of productivity, loyalty, and health, as well as improved cooperation, leadership, and governance [4]. The need for "mastering soft skills for workplace success" has been well established [5,6]. However, professional skills in sustainability are relevant beyond the job market. Lange [7] draws attention to adults' individual pursuits to advance sustainability in their own life and communities, and Lyth et al. [8] highlight the important contribution of third-sector organizations to sustainability transitions. These voluntary, unpaid engagements are people- and project-centered and, thus, professional skills are also relevant here. Despite increasing demand and apparent rewards, professional skills are rarely taught in sustainability programs. Studies show the mismatch between the need for sustainability graduates to master these professional skills and sustainability programs that do not sufficiently teach them $[1,3,9]$. Therefore, students often pick some of them up "on the job" through internships, part-time work, and volunteering. While valuable, these opportunities are on 
their own insufficient to acquire these skills, as on-the-job training often leaves little time for reflection, peer mentoring, and adoption of evidence-supported practices.

Alternative responses start to be implemented. For instance, since January 2017, Australia implemented a set of mandatory higher education threshold standards, including standards related to learning outcomes and assessments. In particular, the generic outcomes, referenced as "knowledge and skills required for employment" and skills "suitable for life-long learning" [10] (p. 4) correspond with the professional skills outlined in this article.

Moving forward, a key question will be how to teach these professional skills in meaningful ways. Teaching and learning professional skills in sustainability will benefit from adopting a whole-person and holistic educational approach, which accounts for cognitive, affective, and psychomotor dimensions of learning. As many of the professional skills in sustainability overlap with personal development and growth, we need to educate head, hands, and heart [11]. Nurturing hope, purpose, love, and peace in a time experienced by many as an era of catastrophe and crisis also brings to the fore the connection between sustainability and spirituality, which increasingly informs sustainability practice in professional and personal contexts [12]. Marques and Dhiman [13] (p. 28) explain how personal development and professional practice in sustainability are related to spiritual development: "the spiritual mindset will enhance one's efforts to act in a sustainably responsible manner, [while] the focus on sustainability will enforce the realization of connectedness with all of life, which is one of the foundations of spiritual thinking." Spiritual development is considered the "'engine' that propels the search for connectedness, meaning, purpose and contribution. It is shaped both within and outside of religious traditions, beliefs and practices" [14].

Acquiring these skills during their higher education would benefit graduates in their professional pursuits. For example, while students choose sustainability programs because they want to make a positive difference [15], they often find themselves overwhelmed when working on sustainability issues. They experience mental and emotional distress because of the urgency, complexity, and intractability inherent in sustainability issues. Similar to other fields in the caring professions sustainability students often feel they are not fast or good enough to make a positive difference, and also experience compassion fatigue $[16,17]$. Therefore, sustainability programs ought to develop preventative self-care skills in students.

Professional skills are well researched in academic disciplines, and professional organizations offer professional development courses and certifications for instance in communication, project management, and teamwork. However, academic materials are often not well suited for an introduction to sustainability students or early career professionals. These materials predominantly focus on only one skill domain and provide overly extensive content (cf. [18]). For example, a standard textbook on project management by [19] is more than a thousand pages long. Furthermore, only few of the available materials discuss professional skills in the context of sustainability.

What is missing is a brief and actionable overview of the professional skills in sustainability and some robust guidelines on how to convey them in higher education. The objectives of this article are, therefore, to propose such an overview and to provide a design for a course on professional skills in sustainability.

After a brief summary of the professional skill domains, synthesized from the literature, we offer a course design, and then discuss its effectiveness against student evaluations and reflections, as well as feedback from professionals. The course was developed and piloted in the undergraduate program in sustainability at Arizona State University, USA, over the past few years ( $N=101$, from 2013 to 2016). This study has been approved by the institutional review board of Arizona State University (approval code: STUDY00005354).

\section{Overview of Professional Skills Relevant to Professional Sustainability Practice}

This section briefly describes six domains of professional skills, namely, preventative self-care, effective and compassionate communication, collaborative teamwork, responsive project management, 
impactful stakeholder engagement, and advanced continuous learning (Figure 1). Based on the current state of knowledge, these seem to be skill domains relevant to sustainability professions. Each domain entails a variety of skills, and domains also overlap (e.g., effective and compassionate communication is relevant to other domains such as collaborative teamwork and impactful stakeholder engagement). We prefaced every domain with an adjective to connect the practice to aspired sustainability outcomes (e.g., collaborative teamwork).

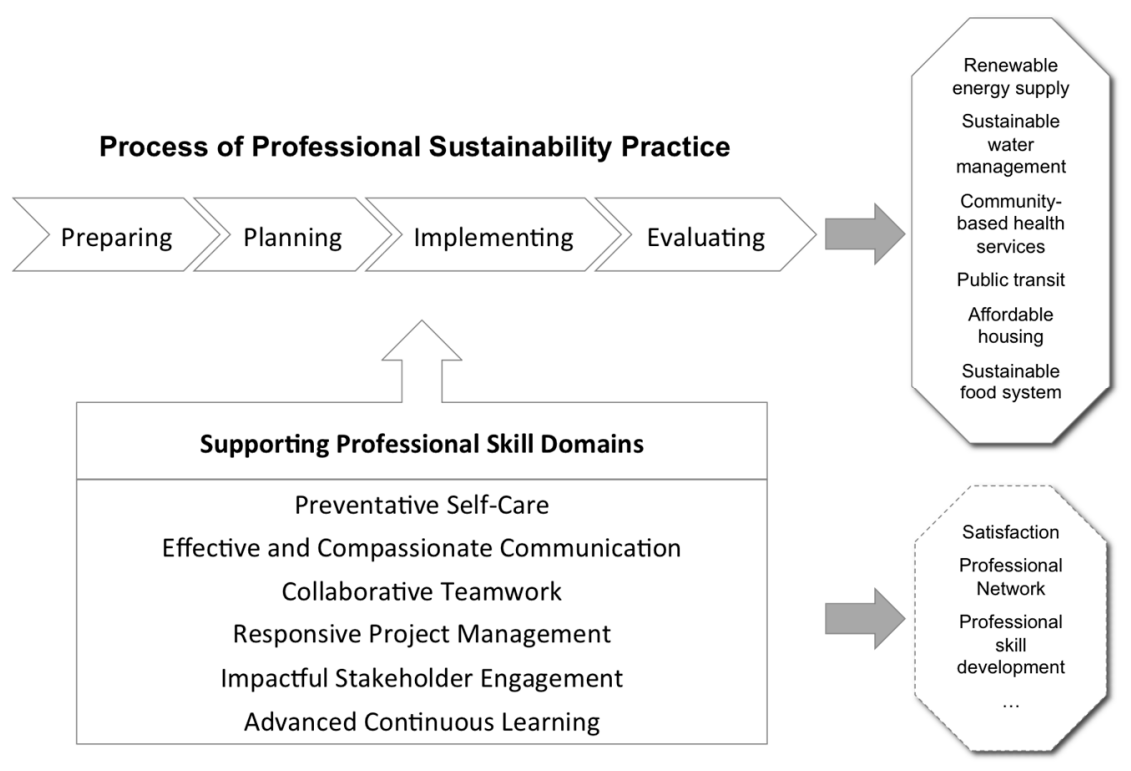

Figure 1. Overview of six professional skills domains relevant to sustainability practice and its outcomes.

Sustainability practices, and by implication the use of professional skills, are embedded in the rich context of issues, places, and people. Figure 2 below illustrates the diverse factors that influence practicing professional skills, using the example of teamwork; similar figures can be created for each skill domain to highlight their contextual embeddedness.

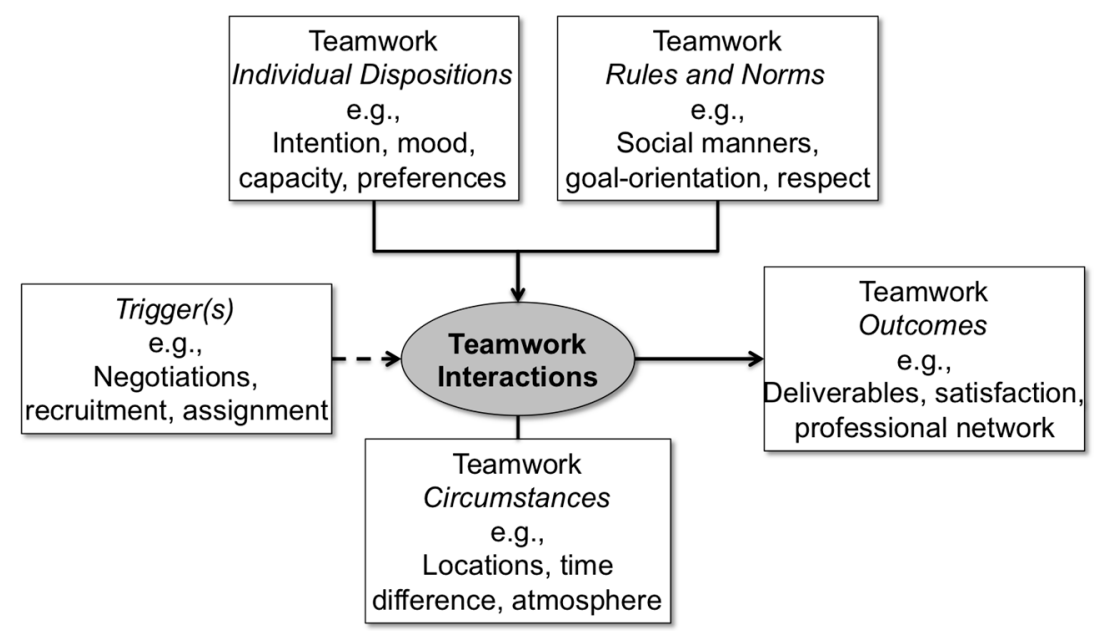

Figure 2. Overview of contextual and personal factors that influence the practice of professional skills, in this example, the practice of teamwork.

At the core of Figure 2 are teamwork interactions. They include, for instance, conducting team meetings, working together on deliverables, as well as evaluating team performance and resolving 
conflicts. Different incidents can trigger these teamwork interactions, e.g., funding for a project came through and now the team can work on the project, starting with co-creating a code of collaboration. Various factors influence team interactions and their outcomes. Individual dispositions of team members include aspects such as personality traits, intention, previous experiences and preferences. Collective rules and norms shaping teamwork include a variety of formal and informal rules ranging from social manners, to the culture of an organization, to formal laws. Another influencing factor are the circumstances within which teamwork takes place: e.g., does the team interact face-to-face or virtual and across different time zones, or, does the meeting space support of hinder collaboration. Outcomes of teamwork interactions pertain to two broad categories: the first refers to the sustainability task of the team (e.g., team produced high-quality products and services) and the second to social outcomes (e.g., team members fostered networks, friendly work environment, personal growth).

Professional sustainability practice employs several skills simultaneously, e.g., teaming, communicating and project-managing effectively. Furthermore, professional skills are thought to work synergistically with content knowledge (e.g., technical expertise related to say sustainable mobility or food systems) and methodical skills (e.g., multi-criteria analysis, scenario development). To keep this article reasonably short, we will not detail the relations between professional skill domains.

\subsection{Preventative Self-Care}

Preventative Self-Care is the process of successfully aligning one's own professional performance with personal wellbeing. It enables professionals to complete their tasks while preventing or coping with negative experiences like distress, frustration, fatigue, or burnout [20].

Preventative self-care is relevant for sustainability professionals, because they aspire to make a positive difference and help averting catastrophe [21]. Sustaining hope and belief in one's agency in the face of slow progress and structural setbacks requires preventative self-care $[17,22]$. Sustainability professionals are part of the caring or helping professions, including among others teachers, nurses and doctors, caretakers and social workers, as well as psychiatrists and counselors. Jobs in these fields have special demands and requirements and caring professionals are known to be prone to suffer stress, compassion fatigue, and burnout [20]. To counter the predominant reactive approach to coping with stress, we chose the preface "preventative" self-care, emphasizing a pro-active approach.

Key activities of preventative self-care relate to four areas. First, they involve successfully managing professional activities, for instance, by setting clear goals, ensuring to comprehend tasks before working on them, and managing one's time. Second, they involve managing one's physical wellbeing at work, for instance, by recognizing how one's daily energy curve progresses through highs and lows and accounting for those when setting priorities and tasks. Physical wellbeing is enhanced by taking breaks, eating well, and doing yoga or exercises to refresh and rewind [23]. Third, they involve managing professional interactions with co-workers, supervisors, clients, and other stakeholders. For instance, developing awareness about one's emotions in these interactions and the habit of taking a few deep breaths in moments of excitement, breaks the impulsive "fight-or-flight response" and thus supports good collaboration [24]. Active listening and taking an interest in the concerns of co-workers also supports productive professional interactions [25]. Fourth, organizing one's work environment also supports wellbeing; along a physical dimension, things like proper lighting and ergonomics of sitting as well has having some plants are recommended. Along a social dimension, this also includes creating a work environment that people perceive as safe [26].

Preventative self-care activities often start with fostering self-awareness and self-compassion. Acting on insights requires abilities for self-motivation, self-regulation, and self-organization. Self-motivation means seeking ways to advance one's own and other's wellbeing (e.g., team members, project participants). Self-regulation means to be aware of one's emotions, thoughts, and behaviors and to process them in support of one's wellbeing. Self-organization refers to developing and maintaining a self-care action plan. 


\subsection{Effective and Compassionate Communication}

Effective and Compassionate Communication is a process involving verbal, non-verbal or written interactions between two or more people that yields agreement, shared information, or asserted support. This kind of communication does not just reach its primary goal, such as delivering a message, i.e., it is not just effective, but also strengthens the relationship between sender and receiver through attentiveness, interest, empathy, and caring, i.e., it is also compassionate [27].

Effective and compassionate communication is relevant for sustainability professionals as a key means to trigger positive change. Moreover, sustainability refers to complex issues that are not easy to communicate, e.g., climate change impacts and responses.

Effective and compassionate communication entails a distinct set of speaking and writing activities. These include, among others: inquiring with other professionals; listening and mapping divergent opinions; explaining complex situations; persuading policy makers; negotiating with contractors; providing feedback to teams; resolving conflicts among stakeholder groups. The key to successful communication is to do it emphatically [28]. The person receiving communication does not just listen or read; they also observe, reflect, and relate to the message. Paying attention to non-verbal, silent cues like facial expression, body posture, and gestures are important components of receiving a spoken message, too [29]. Selecting appropriate communication media and technologies is key to effective and compassionate communication. As mentioned above, communication is an integral part of several professional skills. An example of an overlapping skill connecting preventative self-care, effective and compassionate communication, and collaborative teamwork is self-compassion. According to [30] (p. 146), self-compassion is the skill to emotionally support both oneself (being nurturing and understanding toward oneself, not judgmental) and others (recognizing that all people make mistakes and feel inadequate in some way) when confronted with human imperfection or conflict. Mindfulness is another element of self-compassion: enabling awareness of the present moment, not ignoring, disliking or ruminating about aspects of oneself. Because self-compassion weaves kindness towards self and others as well as mindfulness together, it serves as an "effective emotional regulation strategy", neutralizing "negative emotional patterns" and engendering "more positive feelings of kindness and connectedness" [31] (p. 266). Studies suggest that students with higher levels of self-compassion are more likely to resolve conflicts through compromise, balancing their own and others' needs in fair ways, feeling a sense of autonomy and connectedness [30] (p. 146).

\subsection{Collaborative Teamwork}

Collaborative Teamwork is the process when people engage in utilizing different and complementary types of expertise, skills, and attitudes to complete a task [32]. Collaborative teamwork results in high-quality task delivery (task effectiveness) by co-creating a stimulating and healthy work environment (social process effectiveness) [33].

Collaborative teamwork is relevant for sustainability professionals because of the complexity and scale of sustainability issues at hand [34]. For instance, a project team tasked to develop a viable and evidence-supported concept for developing a sustainable local food system needs to bring in various types of knowledge and skills to complete this task successfully. Knowing how to tap into the diversity of skills that each team members brings to the project can translate into innovative solution ideas, accelerated project success, and cost-effectiveness.

Collaborative teamwork involves a distinct set of interactions: team members collaborate to manage the project; they collaborate with each other and other stakeholders to co-create project deliverables, and they engage socially, to bond and build a basis of trust. Teaming entails numerous activities starting with aligning the team to build commitment and a shared purpose. Preparing for team meetings, e.g., by creating an agenda, preparing discussion points, and reviewing documents ahead of the meeting, will make these interactions productive [35]. Individual and collective accountability, e.g., expressed by arriving to meetings on time or by following through with assignments, builds trust in the team process. Thoughtful communication within the team, e.g., 
by sharing appreciation and critique, and constructively addressing disagreement and tensions, supports the team's creativity and productivity as well as individual team members' wellbeing [36].

\subsection{Responsive Project Management}

Responsive Project Management is the structured process of achieving aspired project outcomes within a given timeframe, budget, and other constrains [19]. A key success factor is that the constituency-the clients, stakeholders, customers, and/or users-accepts and uses the project outcomes [37].

Responsive project management is relevant for sustainability professionals because it offers a method to plan for positive change while accounting for uncertainties that require adaptation. Triggering change towards sustainability involves shifts in mindsets, values, and behaviors. Such undertakings face obstacles and resistance. Responsive project management allows for maneuvering and navigating a project through these challenges [38].

In order to achieve project success, responsive project management emphasizes the skill to anticipate necessary changes to the project scope, process, and even the culture or policies of an organization. Exemplary activities pertaining to responsive project management include: organizing the project process as part of a dynamic system by accounting for surprise and contingency plans; providing good time management to facilitate engagement of project participants; and carefully monitoring and strategically reflecting about the process and warranted adjustments. Responsive management is not a straight jacket. It is meant to be a reflective and adaptive process, based on thoughtful actions that consider how the project is embedded in a wider context, accounting for diverse stakeholder groups and unpredictable developments. Responsive project management serves as a backbone and anchor point that allows the project to be open to change and to respond flexibly while pursuing project objectives.

\subsection{Impactful Stakeholder Engagement}

Impactful Stakeholder Engagement is the collaboration between sustainability professionals and people who have a stake in the process and outcomes of a given project $[39,40]$. Impactful stakeholder engagement engages diverse stakeholders from government, businesses, and civil society. It aims to yield task outcomes like quality project deliverables that have been informed by a plurality of views and are broadly accepted, as well as social outcomes including new perspectives, relationships and built capacity [41].

Impactful stakeholder engagement is relevant for sustainability professionals because it allows applying the concept of sustainability in practice and critically discussing who would be impacted and in what ways. As change towards sustainability affects everyone, impactful stakeholder engagement facilitates understanding and acceptance of innovations towards sustainability.

Key activities of impactful stakeholder engagement occur along a progressive sequence of interactions starting with organizing listening sessions that allow stakeholders to air concerns, impressions, ideas (opening up to a range of inputs). The next step includes facilitating open and productive discussions among diverse or homogeneous stakeholder groups in order to deepen their inputs and incorporate them into the project. Later stage activities then include collaborating with stakeholders on project deliverables and eliciting feedback from stakeholders on these project deliverables [42]. There are various techniques, tools and settings to support these activities ranging from face-to-face conversations to online surveys; tools offering higher and lower levels of interaction can be combined to further facilitate the co-creation of meaning and deliverables [43].

\subsection{Advanced Continuous Learning}

Advanced Continuous Learning is the process of expanding one's technical expertise (knowledge and procedures), professional skills, and attitudes by using appropriate procedures in a purposeful and self-directed way. The goal of advanced continuous learning is to effectively enhance professional 
performance and successfully deal with short- to long-term emerging challenges and new requirements over the lifespan of one's professional sustainability career [44]. The majority of learning happens as informal learning [45]. Believing in the ability to learn and grow is a foundational driver for success [46].

Advanced continuous learning is relevant for sustainability professionals as sustainability is a rapidly evolving field. Professionals require being up to date on emerging sustainability problems and evidence-supported sustainability solutions. More importantly they require learning differently, as conventional learning and formal education fail to contribute to a sustainable future [47]. Advanced continuous learning entails the ability of sustainability professionals to reflect on beliefs, worldviews, and values and how they shape problem framing, solution development, and current practices [48]. Transformative learning occurs when these reflections lead to alternative insights, motivating personal change in practices [47].

Advanced continuous learning emphasizes proactive over reactive, and transformative over adaptive learning in order to help us generate deep insights about sustainable solution approaches [42]. Clear learning goals as well as an appraisal of what one knows relative to these goals help orient learning activities, involving individual learning actions and collaborative learning interactions. Drawing on experiential learning approaches (cf. [49]), learning actions cycle through adopting information (e.g., listening, reading/observing, writing, interacting with others); applying, experiencing, and experimenting; and reflecting, analyzing success and failure, as well as synthesizing and adjusting what was learned. Learning interactions range from teaching each other, to imitating mentors, to hands-on working and crafting together.

This section offered a synopsis of the six professional skills domains. The next section presents one approach to teach and learn these skills: through a course in a sustainability program at a higher education institution.

\section{An Exemplary Course on Professional Skills in Sustainability}

We present the design of the professional skills course mandatory for all sophomore (2nd-year) undergraduate students enrolled in the sustainability program of Arizona State University. The course was first offered in Fall 2013 as a one-credit course and will be continued as a three-credit course as of Fall 2017. Between Fall 2013 and Fall 2016, 101 students completed the in-person course.

In the following, we describe the learning objectives, learning settings, course structure, and course assignments.

The course was designed in a way that after its completion, students would be able:

(1) To explain and discuss why professional skills, in general and specifically, are important for sustainability professionals, using examples of application.

(2) To apply professional skills in sustainability practice.

(3) To evaluate their own and team members' professional skill levels based on a set of justified quality criteria.

(4) To define strategies, techniques, and tools for learning and advancing professional skills that can further direct students' / graduates' professional development.

In designing the course, we drew on concepts such as "constructive alignment" and "backward design" [50,51]. These concepts ensure that learning objectives are matched with effective learning settings and with appropriate assessments to measure students' progress towards the objectives.

We integrate the following learning settings into the course to support students in achieving the course's learning outcomes: familiarizing with skills through readings, guest lectures, and discussions; practicing skills in the classroom; applying skills in a real-world project where students work in a team and engage stakeholders; and reflecting on the acquisition of skills. Table 1 shows the course modules each related to a professional skills domain. It highlights the team assignments intended 
to build professional skills and illustrates how the real-world project serves as a vehicle for students' professional development.

Table 1. Overview of the course structure, team assignments, and the real-world team project.

\begin{tabular}{|c|c|c|c|}
\hline $\mathbf{M}$ & Module Title & Team Assignments & Team Project \\
\hline 1 & Introduction & & \\
\hline a & Introduction to course & \multirow{2}{*}{$\begin{array}{l}\text { Self-organize a team } \\
\text { building activity }\end{array}$} & \\
\hline $\mathbf{b}$ & Introduction to team project (flea-market) & & \\
\hline 2 & Preventative Self-Care & & \\
\hline a & Discussion with Guest Speaker & \multirow{2}{*}{$\begin{array}{l}\text { Develop team-care plan, } \\
\text { incl. a code of collaboration }\end{array}$} & \\
\hline b & Practice & & \\
\hline 3 & Effective \& Compassionate Communication & & \\
\hline a & Discussion with Guest Speaker & \multirow{2}{*}{$\begin{array}{l}\text { Listen actively, and } \\
\text { communicate mindfully }\end{array}$} & \\
\hline $\mathrm{b}$ & Practice & & Draft presentation \\
\hline 4 & Collaborative Teamwork & & \\
\hline $4 a$ & Discussion with Guest Speaker & \multirow{2}{*}{$\begin{array}{l}\text { Evaluate team roles, incl. } \\
\text { functional \& social roles }\end{array}$} & \\
\hline $4 \mathrm{~b}$ & Practice & & \\
\hline 5 & Responsive Project Management & & \multirow{3}{*}{$\begin{array}{l}\text { Students work in } \\
\text { teams on real-world } \\
\text { project as one of } \\
\text { their assignments }\end{array}$} \\
\hline $5 a$ & Discussion with Guest Speaker & \multirow{2}{*}{$\begin{array}{l}\text { Create a Gantt-chart for } \\
\text { project to illustrate work } \\
\text { plan along temporal scale }\end{array}$} & \\
\hline $5 b$ & Practice & & \\
\hline 6 & Impactful Stakeholder Engagement & & \\
\hline $6 a$ & Discussion with Guest Speaker & \multirow{2}{*}{$\begin{array}{l}\text { Observe stakeholder } \\
\text { engagement in action and } \\
\text { synthesize lessons }\end{array}$} & \\
\hline $6 b$ & Students go on fieldtrip & & Final presentation \\
\hline 7 & Advanced Continuous Learning & & \\
\hline $7 a$ & Discussion with Guest Speaker & \multirow{2}{*}{$\begin{array}{c}\text { Compare learning } \\
\text { strategies synthesize team } \\
\text { learning strategy }\end{array}$} & \\
\hline $7 \mathrm{~b}$ & Practice & & Review portfolio \\
\hline 8 & Synthesis & & \\
\hline $8 a$ & Synthesis of tools developed as a class & \multirow{2}{*}{$\begin{array}{l}\text { Reflect on self- \& peer- } \\
\text { evaluation and } \\
\text { improvement potential }\end{array}$} & Revised report \\
\hline $8 \mathrm{~b}$ & Synthesis of tools along project life cycle & & Final portínolio \\
\hline
\end{tabular}

The course is linked to a small real-world sustainability project sponsored by an external partner such as the university administration, a city department, or a local business (cf., [52,53]). Students work on an agreed upon sustainability issue in teams of four to five, supported by a coach (course instructor), and in collaboration with their project partner. The project needs to be conducted in a timely manner and with deliverables that meet academic and practical expectations. As the course focuses on building professional skills, the sustainability issue needs to be relevant to the project partner, while not centering students' attention exclusively on the issue. In past projects, students worked on assessing the sustainability of different toilet types to support facilities managers' investment decisions; or students planned a sustainable flea market to raise the funds for a community school garden. As students start to investigate the sustainability issue, they are expected to select and 
employ professional skills, e.g., communicating effectively and compassionately with each other, the team coach, and the project partner; building a cooperative team and creating productive teamwork settings; employing responsive project management techniques; enabling and facilitating individual and collective learning; and practicing preventative self-care. Through the project, the course simulates sustainability practice in a professional setting, facilitating students' understanding and practicing of the skills as well as demonstrating their relevance for future careers.

The class sessions alternate between discussion sessions and practice sessions. The discussion sessions are based on a textbook that details the six skill domains [54]. Using a seminar format, each discussion section introduces a skill domain and facilitates a conversation with a professional, who joins the class as guest speaker to share how to employ the respective skill in professional practice. Professionals involved in the course included, among others, certified team coaches, communication trainers, and project managers. The practice sessions are designed to enact skills through embodied learning interactions like role-play, taking the hot-seat, or mindful listening [55,56]. Role-play puts students in groups to work on a real-world task, say, to plan a stakeholder engagement workshop to elicit input on a municipal proposal to increase water rates for indoor and outdoor use. Students receive cards with descriptions about their roles (e.g., councilor, resident in support or against rate increase, facilitator) and ways they enact their roles (being agitated, calm, or absent-minded on the cell phone). After a while of playing, the groups step out of their roles and engage in a reflection of the experience. For the mindful listening activity, students are paired. Every student thinks about say an experience of belonging and shares this experience while the others are just listening with open ears, soft eyes, and no intention to respond, comment, or judge on what they hear (adapted from [57]).

Alternating discussion and practice sessions supports students in familiarizing with, practicing, applying, and reflecting on professional skills and their acquisition.

The assignments are structured into individual assignments and collaborative team assignments. The individual assignments are designed for students to capture their thoughts in preparation of team working sessions. For instance, related to exploring learning preferences and strategies, we ask students to characterize their learning preferences ahead of the meeting (using the Felder-Silverman Learning Style Index [58]). Students bring the results from this activity and their written reflection to the team meeting, where they compare and contrast their learning strategies and explore how they could support each other's learning. Another individual assignment involves writing a reading response to each textbook chapter and students own personal skill practice pertinent to the chapter's skill domain, drawing on the method of articulated learning [59]. After the reading, students identify one particular skill that seems relevant to their personal situation, e.g., anticipation and time management as part of responsive project management. Students develop a plan how to learn and rehearse this specific skill, implement the plan, and at the end, reflect on their mastery of professional skills against good practices recommended in the textbook and by the guest speakers.

The collaborative team assignments address the project deliverables to be produced for the project partner, engage teams in working together on professional tools, and capture reflections on the team process. Each team assignment entails the adoption of the tool (e.g., create a Gantt-chart) and a collective reflection on how the team worked with the tool over the course of the project.

To build their "tool belt" of professional skills, students produce an individual portfolio of practices and tools applied over the course of the semester (Figure 3). The portfolio is supposed to demonstrate the professional skills acquired [60,61].

We use a variety of assessment approaches and techniques, including real-time performances, written documents, and creation of flowcharts and other graphics. However, the majority are performance-based assessments (e.g., project work, reflective reading responses, and portfolio) assessing reflection capacity, sense of relevance, application capacity, anticipation capacity, and creativity [50]. 

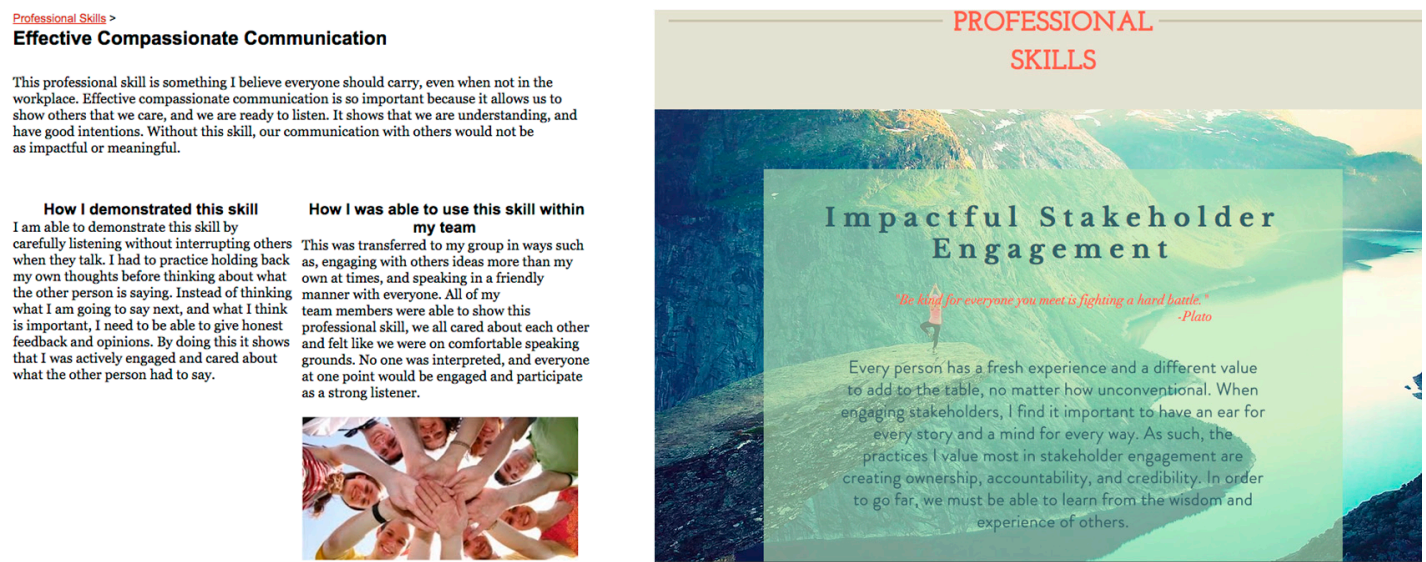

Figure 3. Illustrations of students' portfolios. The portfolio at the left describes the skill domain and offers examples of how the student applied the skill to her individual practice and to a professional team setting. The portfolio at the right uses an artistic approach to emphasize the student's approach to skill practice.

\section{Students' Evaluations and Experts' Perspectives on the Course}

This section presents the results for the second research question, asking: (i) to what extend did the course enabled students to meet learning objectives overall; and (ii) for each of the four learning objectives specifically? The learning outcomes were chosen as focal points for the data, because, per the degree program, this is what the course should enable students in achieving. The learning outcomes relate to the professional skill domains as students are expected to be able to discuss and employ professional skills in each domain as well as evaluate their practice and identify ways to further enhance their practice.

To address these questions, we draw on the sample of voluntary and anonymous student course evaluations in which students evaluate the course. Students rate standardized statements using a five-point Likert-scale including strongly agree (SA), agree (A), neither agree nor disagree $(\mathrm{N})$, disagree (D) and strongly disagree (SD). Additionally, students' qualitative feedback, provided in additional comments, demonstrates how the course helped students to make progress towards the learning objectives. Results reflect responses from 44 out of 101 students with response rates varying over the years (Table 2).

Table 2. Response rates 2013-2016 of the evaluation survey for the professional skills course.

\begin{tabular}{ccccccc}
\hline $\begin{array}{c}\text { Semester, Year, } \\
\text { Session }\end{array}$ & $\begin{array}{c}\text { Fall 2013 A } \\
\text { Session }\end{array}$ & $\begin{array}{c}\text { Fall 2013 B } \\
\text { Session }\end{array}$ & Spring 2014 & Fall 2015 & Spring 2016 & Fall 2016 \\
\hline $\begin{array}{c}\text { Responses/Overall } \\
\text { Cohort }\end{array}$ & $10 / 21$ & $7 / 13$ & $3 / 13$ & $4 / 15$ & $9 / 21$ & $11 / 18$ \\
Response Rate & $48 \%$ & $54 \%$ & $24 \%$ & $27 \%$ & $43 \%$ & $61 \%$ \\
\hline
\end{tabular}

The research involved a qualitative approach for data collection and analysis, manually coding students written feedback. Given the evaluative purpose of this research, the codes were derived from the themes entailed in the learning objectives. For instance, the codes for learning objective 1 relate to the objective's definition "to explain and discuss why professional skills are important for sustainability professionals" [62]. The purpose is to capture students' meaning making of the course's learning objectives and their reflections on attaining these objectives. 


\subsection{Does the Course Enable Students to Meet the Learning Objectives?}

The majority of students evaluated the course as valuable, allowing them to develop professional skills and make progress toward the learning objectives (Table 3).

Table 3. Students' ratings of learning objectives and content, averaged 2013-2016.

\begin{tabular}{lccc}
\hline \multicolumn{1}{c}{ Evaluative Statement } & $\begin{array}{c}\text { Strongly } \\
\text { Agree/Agree }\end{array}$ & $\begin{array}{c}\text { Neither Agree nor } \\
\text { Disagree }\end{array}$ & $\begin{array}{c}\text { Disagree/Strongly } \\
\text { Disagree }\end{array}$ \\
\hline The learning objectives of the course were met. & $73 \%$ & $20 \%$ & $7 \%$ \\
I gained an understanding of major concepts in the field. & $72 \%$ & $4 \%$ & $24 \%$ \\
I learned important skills in this course. & $62 \%$ & $12 \%$ & $26 \%$ \\
Overall I learned a great deal from this course. & $61 \%$ & $17 \%$ & $22 \%$ \\
\hline
\end{tabular}

In the following sections, we illustrate how the course helped students achieve each learning objective, drawing on students' qualitative comments.

\subsection{Learning Objective 1: To Explain and Discuss Why Professional Skills, in General and Specifically, Are Important for Sustainability Professionals, Using Examples of Application}

The course helped some students to reflect on the content learned in other classes through the lens of the professional skills, which offered an actionable perspective. One student wrote: "[the course] provided me with a bigger scope of what the function of sustainability is and how it operates on a day-to-day basis. In a lot of my other classed I learned more general information about what sustainability is." (Fall 2016) For another student, the course offered a window to understand professional expectations: "The focus on [... ] the skills that a professional will need in the field of sustainability was very helpful and helped me gain a better understanding of what sustainability professionals do and what would be expected of me when I have a job in this field." (Fall 2016) Effective vehicles for students to make progress towards this learning objective are the invited guest speakers. Almost all students valued the opportunity to learn from the professional experts who "are actually out in the field that we want to go in." (Spring 2016) These encounters gave students the opportunity to receive "answers to our direct concerns with becoming a sustainability professional and how to execute certain skills" (Fall 2015) and to connect theory with practice, as "[t]heory is only one thing but when you get to listen to and question people about their own personal experiences, you gain a lot." (Spring 2016)

\subsection{Learning Objective 2: To Apply Professional Skills in Sustainability Practice}

Some students' comments detailed their learning of applying professional skills. Some skills such as "team collaboration, project management, and communication especially" are seen as immediately relevant and applicable, for example, in other project-based courses [53]. Other skills seem less readily accessible at this stage, yet not less relevant. One student stated: "I think I learned skills which might not easily be able to practice now such as stakeholder engagement, but other skills such as how to set up a work plan for a group and practicing caring self-management are skills that I can easily use in my future classes." (Fall 2016) As intended by the design of the course, the team project served as the vehicle to apply and practice professional skills. One student wrote: "The most valuable part was the team project that culminated with a professional project proposal. It gave us an opportunity to develop team working skills, facilitation skills, project management and time management skills, and real-life experience with engaging stakeholders and working on sustainability issues." (Spring 2014)

\subsection{Learning Objective 3: To Evaluate Their Own and Team Members' Professional Skill Levels Based on a Set of Justified Quality Criteria}

The ability to evaluate mastery of skills was hardly mentioned in the comments offered by students. Nevertheless, a few students shared remarks about how the course supported their personal 
development. As helpful vehicles fostering their personal growth, students identified "the generous amount of feedback for every assignment", the class discussions and role-plays (Fall 2013A) as well as being asked "to reflect on their own personal goals, challenges, and strategies." (Fall 2013B)

\subsection{Learning Objective 4: To Define Strategies, Techniques, and Tools for Learning and Advancing Professional} Skills that Can Further Direct One's Professional Development

No student commented explicitly whether the course supported them in developing their own learning strategies as part of their own, self-directed continuous learning efforts. Nevertheless, students consistently appreciate the team assignment that explores individual learning strategies and develops a team learning strategy, because it gives them a tool to enhance the knowledge and productivity of the team. One student (Spring 2014) demonstrated in two ways how to own the idea of self-directed learning. Students work with the textbook as supplemental material to help deepen class content and transfer their insights to other activities: "The text for this class is a good addition to the material learned in class. It provides a lot of great strategies for teamwork and project management. [ . . the instructor] really stressed [ . . ] the importance of being able to look at our coursework, internship, etc. and identify skills we learned [ ... ] that can apply to other situations. I think this is a really important thing [ ... ] to be able to do. The skills [ ... ] I learned in this class have real world relevance, and I know I will be glad to have them in the future."

\section{Discussion}

While the course received in general positive feedback, some improvements are necessary to effectively reach the learning objectives. The improvements concern adjustments to learning activities and assessments, in particular to those preparing students for evaluating mastery of skills and devising continuous learning strategies. The goal is to further support students in learning, internalizing and employing professional skills and attitudes. Challenges pertain to striking a productive balance between learning and application: letting students learn about skills and applying them in a timely manner or at least anticipating that in due time they will be required to employ the skills in a future school project, a sustainability job, voluntary citizen engagement, or personal pursuits.

Students collectively advised to offer the course as a three-credit course to have more time to work on each professional skill domain. This request was approved by the undergraduate program committee (three-credit course as of Fall 2017).

Another adjustment concerns that students are challenged by the complexity of the course, understanding their tasks, and using creative approaches to problem solving. These challenges, while different from other classes, reflect students' future job situation, where they might receive an initial brief and are expected to figure it out on their own. While some students capitulated others succeeded: "[ ... ] it was laid out like an episode of Sherlock Holmes. We learned all these different concepts, tools and things like that, and in the beginning [ ... ] I didn't understand what the points of all the tools were. But then within the last few classes, everything came together." (Fall 2013A) While dealing successfully with these challenges will remain part of the intended learning experience, the instructors need to provide more scaffolding for this process [63]. This could be done through collectively mapping out the pathway of the course; clarifying the expectation that students need to self-organize and self-direct their project and approach instructors with questions; and further supporting the collective synthesis of what was learned at the end of the course. This adjustment illustrates the challenge of simulating a professional work setting that enables students to work towards a professional output, as opposed to working toward an A-grade. In addition, the physical layout of most classrooms is not conducive to simulating a professional work setting either.

Specific adjustments to learning settings and assessments are planned to enable better attainment of learning objectives.

Regarding learning objective 3 (performance evaluation): Tutored and facilitated in-class activities seem to be particularly beneficial at the beginning of the course in order to enable students in creating 
a supportive learning environment themselves that uses formative evaluation to support learning. As one student explored: "I really liked the listening exercise we did on the last day. It helped me feel more connected with my peers. Having that connection builds camaraderie [and] allows us to work better as a cohesive and compassionate team. I would have loved to do something similar in the beginning of the course to frame our interactions for the rest of the semester." (Fall 2016)

Furthermore, students also reported that they found the facilitated discussions and reflections in class and in teams more supportive of their learning than individually written reading reflections. These feedbacks highlight the need to adopt the pedagogical concept of the "flipped classroom" for this course, and engage embodied learning and peer-evaluation more. The flipped classroom has students learn at home (readings, video-recorded lessons) and use class time to engage this content through activities that deepen the engagement with the material $[64,65]$. To this end, embodied learning goes beyond class discussions engaging cognitive dimensions; it allows students to practice professional skills reinforcing the idea of learning with "head, hands and heart" [11]. Adopting the "flipped classroom" approach requires extra efforts on the instructors' side but brings reading and self-studied material to life and opens a door to explore together the role of emotions in professional skill practice. Together, these activities allow collectively identifying quality criteria for performance evaluation and role modeling how to evaluate skill practice. Learning assessments need innovation to provide students with useful guidance. To assess students' ability to evaluate their mastery of skills and communicate feedback, we are currently creating for each skill domain a set of real-world scenarios for teams to solve. Students will be required to record their team meetings early in the semester and review their video-footage against the quality criteria identified in class. Review of recordings and written reports in class is one way to collectively assess what skills and practices students integrate, how, and why. Additionally, students' individual portfolios will be assessed not only related to how skill mastery is presented but also related to their self-evaluation skills [61]. The goal of these activities and assessments is to foster students' ability to strategically reflect on professional skills, and less to assess pre- and post-course levels of competencies. Any type of self-and peer performance evaluation benefits from students using a self-compassion approach [31].

Regarding learning objective 4 (learning strategies for continuous professional development): This learning objective is challenging because many students are primarily concerned with succeeding in the program "now" and less with succeeding in a professional environment in the future. However, the preventative self-care is a professional skill domain that has relevance right now for all students and it could be used as a hook to inspire students' individual thinking around their learning strategy starting with a learning strategy for holding hope. The class could jointly reflect on how interpersonal competence and professional skills are relevant to positive change. Exemplary and broad questions to start this exploration could include: Does the work on the team project for the client stimulate a transformation within us? Does the project contribute to a transformation in the world? The discussion could be framed in the context of transformative learning and progressively explore how to do "things better", to how to do "better things" and finally to how "see things" differently [47].

Students could explore the idea that creating change towards sustainability requires us to experience change within ourselves in the first place. The assessment would focus on the ability to devise a learning strategy by using contemplative practices that help us recognize inspiring and empowering seeds of hope (cf., resources provided by [4,66]). Transformative learning could be extended to advance intercultural competencies, employing professional skills in diverse cultural settings and in sustainability work more broadly. Consider incorporating a "pen-friend" as part of students' reflective writing assignments. Higher education institutions can now draw on a network of sustainability schools and programs. As pen-friends, students, using online technologies, can explore the cultural dimensions of professional skills applied to their project as well as applied to their personal learning about changing oneself. Such exchanges deepen critical reflection on professional skills in sustainability, e.g., how place and culture shape learning and employing professional skills, and helps developing cultural sensitivity [67]. 
Concluding the discussion about how to improve an introductory course on professional skills in sustainability, we like to draw attention to other ways to teach professional skills. For example, curricular learning opportunities include a course, as well as service-learning or internship programs, which allow students to reflect how they employ professional skills at the organization and to apply evidence-supported practices from the textbook. There is also a suite of extracurricular options to learn about professional skills, such as volunteering in sustainability organizations or personal sustainability pursuits. The challenge might be to carve out time to pause and reflect on one's practice as well as to research evidence-supported additional or alternative practices.

\section{Conclusions}

Research highlights the gap between what professional skills sustainability programs convey vs. what the job market as well as collectively organized sustainability pursuits, e.g., spearheaded by third sector organizations, ask for. Few programs teach students professional skills in support of their future sustainability practice. This article presented an overview of the professional skills in sustainability and one approach, an introductory course designed to build students' capacity in these skills.

We identified six professional skill domains of relevance, including preventative self-care, effective and compassionate communication, collaborative teamwork, responsive project management, impactful stakeholder engagement, and advanced continuous learning. Each skill domain entails a diversity of specific skills. Thus, course instructors ought to select the most appropriate ones in response to students' circumstances and aspirations. The selection should also account for the fact that part-time students who are mid-career professionals and caretakers are expected to become the majority of the (undergraduate) student body [68].

Introducing such a course as a mandatory part of the curriculum, and learning semester by semester, allows us to contribute to the discourse on sustainability in higher education and its contribution to real-world problem-solving beyond responding to demands from the job market.

Professional skills are relevant for jobs in sustainability, and more importantly, they are relevant for sustainability writ large. Sustainability problems and proposed solutions, on the local or international level, are often discussed from polarized perspectives of what "the best" solution is. While sustainability expertise and technical knowledge undoubtedly need to inform problem framing and solution development, professional skills are needed to bring these to fruition, e.g., through empathic conversations. Willer [69] argues that empathy and respect are essential to build bridges because they enable us to "really listen to one another, to understand one another's values and to think creatively about why someone with very different political and moral commitments from their own should nonetheless come to agree with them."

Putting professional skills in the context of longer-term sustainability transitions indicates how thoughtfully employing professional skills can help moving "old debates" into new ways of exploration. For instance, can we innovate conventional ways of project-management by changing the metrics for monitoring and controlling? Currently, the primary metrics is effectiveness (creating outcomes and results). This expectation shapes the design of projects around outcomes that sustainability professionals deem achievable; projects become smaller and less audacious, but not less taxing. In contrast, Parker Palmer [70] advocates adding faithfulness to effectiveness. By faithfulness, he means being faithful to one's own gifts and those of others and that the intersection creates collaborative processes that are "life-giving" as opposed to draining.

Professional skills are relevant because they allow teachers and learners to experience how changing our daily professional routines takes work and yields social benefits beyond the individual. This personal experience of aspiring to change as well as planning and implementing change is a humbling and empowering experience, offering insights for engaging professionally and personally in larger transformations. Change starts within, not outside, ourselves.

It is important to keep in mind these bigger purposes of using professional skills to sustain ourselves in long-term transformations; otherwise, the practice of professional skills easily becomes an 
instrument to increase productivity within the status quo as opposed to becoming a practice that helps questioning and changing the status quo over prolonged periods.

Acknowledgments: We would like to thank Tamsin Foucrier and Braden Kay (Ph.D.) for their contributions to the development of the professional skills course and the accompanying textbook. We would also like to thank two anonymous reviewers for their careful review of this article and thoughtful requests for revisions.

Author Contributions: Both authors have equally contributed to this article.

Conflicts of Interest: The authors declare no conflict of interest.

\section{References}

1. MacDonald, L.; Shriberg, M. Sustainability leadership programs in higher education: Alumni outcomes and impacts. J. Environ. Stud. Sci. 2016, 6, 360-370. [CrossRef]

2. Wiek, A.; Withycombe, L.; Redman, C.; Mills, S. Moving Forward on Competence in Sustainability Research and Problem Solving. Environ. Sci. Policy Sustain. Dev. 2011, 53, 3-13. [CrossRef]

3. Willard, M.; Wiedmeyer, C.; Flint, W.R.; Weedon, J.S.; Woodward, R.; Feldman, I.; Edwards, M. The sustainability professional: 2010 Competency survey report. Environ. Qual. Manag. 2010, 20, 49-83. [CrossRef]

4. Greater Good Science Center. Available online: http://greatergood.berkeley.edu/channel/work_career/ manifesto (accessed on 17 February 2017).

5. US Department of Labor's Office of Disability Employment Policy. Soft Skills to Pay the Bills-Mastering Soft Skills for Workplace Success. 2012. Available online: https:/ /www.dol.gov/odep/topics/youth/softskills/ softskills.pdf (accessed on 17 February 2017).

6. Mitchell, G.W.; Skinner, L.B.; White, B.J. Essential soft skills for success in the twenty-first century workforce as perceived by business educators. J. Res. Bus. Educ. 2010, 52, 43-53.

7. Lange, E.A. Thinking beyond Borders: Global Ideas, Global Values; Online Proceedings; Groen, J., Guo, S., Eds.; Canadian Association for the Study of Adult Education (CASAE); L'Association Canadienne Pour L'ÉTUDE de L'Éducation des Adultes (ACÉÉA): Vancouver, BC, Canada, 2008; pp. 213-218.

8. Lyth, A.; Baldwin, C.; Davison, A.; Fidelman, P.; Booth, K.; Osborne, C. Valuing third sector sustainability organisations-qualitative contributions to systemic social transformation. Local Environ. Int. J. Justice Sustain. 2017, 22, 1-21. [CrossRef]

9. Allen, J.H.; Beaudoin, F.; Lloyd-pool, E.; Sherman, J. Pathways to Sustainability Careers: Building Capacity to Solve Complex Problems. Sustainability 2014, 7, 47-53. [CrossRef]

10. Commonwealth of Australia. Tertiary Education Quality and Standards Agency Act 2011 and Higher Education Standards Framework (Threshold Standards) 2015; Federal Register of Legislative Instruments F2015L01639; Australian Government Department of Education and Training: Canberra, Australia, 2015.

11. Sipos, Y.; Battisti, B.; Grimm, K. Achieving transformative sustainability learning: Engaging head, hands and heart. Int. J. Sustain. High. Educ. 2008, 9, 68-86. [CrossRef]

12. Dhiman, S.; Marques, J. (Eds.) Spirituality and Sustainability, New Horizons and Exemplary Approaches; Springer: Cham, Switzerland, 2016.

13. Marques, J.; Dhiman, S.; King, R. Exploring the Link between Spirituality and Sustainability. Bus. Renaiss. Q. 2010, 5, 19-29.

14. Zakrzewski, V. The Case for Discussing Spirituality in Schools. 2013. Available online: http:/ /greatergood. berkeley.edu/article/item/how_to_discuss_spirituality_in_school (accessed on 17 February 2017).

15. Shriberg, M.; Macdonald, L. Sustainability leadership programs: Emerging goals, methods and best practices. J. Sustain. Educ. 2013, 5, 1-21.

16. Kelsey, E.; Armstrong, C. Finding hope in a world of environmental catastrophe. In Learning for Sustainability in Times of Accelerating Change; Wals, A.E.J., Corcoran Blaze, P., Eds.; Wageningen Academic Publishers: Wageningen, The Netherlands, 2012; pp. 187-200.

17. Holroyd, J. Self-Leadership and Personal Resilience in Health and Social Care; SAGE: Los Angeles, CA, USA, 2015.

18. Oakley, B.; Felder, R.M.; Brent, R. Turning student groups into effective teams. J. Stud. Cent. Learn. 2004, 2, 9-34. 
19. Kerzner, H.R. Project Management—A Systems Approach to Planning, Scheduling, and Controlling; Wiley: London, UK, 2013.

20. Skovholt, T.M.; Trotter-Mathison, M.J. The Resilient Practitioner: Burnout Prevention and Self-Care Strategies for Counselors, Therapists, Teachers, and Health Professionals; Routledge: New York, NY, USA, 2014.

21. Savage, E.; Tapics, T.; Evarts, J.; Wilson, J.; Tirone, S. Experiential learning for sustainability leadership in higher education. Int. J. Sustain. High. Educ. 2015, 16, 1467-6370. [CrossRef]

22. Gardiner, S.; Rieckmann, M. Pedagogies of Preparedness: Use of Reflective Journals in the Operationalisation and Development of Anticipatory Competence. Sustainability 2015, 7, 10554-10575. [CrossRef]

23. Hamer, W.; Bornand, J. Überfachliche Kompetenzen: Techniken und Strategien zur Förderung der Selbstkompetenz; Compendio Bildungsmedien: Zürich, Switzerland, 2012. (In German)

24. Goleman, D.; Boyatzis, R.; McKee, A. Primal Leadership; Harvard Business School Press: Boston, MA, USA, 2013.

25. Segal, E.J. Social empathy: A model built on empathy, contextual understanding, and social responsibility that promotes social justice. Soc. Serv. Res. 2011, 37, 266-277. [CrossRef]

26. Edmonson, A.C. Building a Psychologically Safe Workplace. TED Talk. 2014. Available online: https: / /youtu.be/LhoLuui9gX8URL (accessed on 26 December 2016).

27. Hargie, O. (Ed.) The Handbook of Communication Skills; Routledge: London, UK; New York, NY, USA, 2006.

28. Godemann, J.; Michelsen, G. Sustainability communication-An introduction. In Sustainability Communication. Interdisciplinary Perspectives and Theoretical Foundations; Godeman, J., Michelsen, G., Eds.; Springer: Dordrecht, The Netherlands, 2011; pp. 3-11.

29. Mehrabian, A. Silent Message; Wadsworth: Belmont, TN, USA, 1971.

30. Yarnell, L.M.; Neff, K.D. Self-compassion, Interpersonal Conflict Resolutions, and Well-being. Self-Identity 2013, 12, 146-159. [CrossRef]

31. Neff, K.D.; Hsieh, Y.-P.; Dejitterat, K. Self-compassion, achievement goals, and coping with academic failure. Self-Identity 2005, 4, 263-287. [CrossRef]

32. Edmondson, A.C. Teaming: How Organizations Learn, Innovate, and Compete in the Knowledge Economy; Wiley: London, UK, 2012.

33. West, M.A. Effective Teamwork Practical Lessons from Organisational Research; John Wiley \& Sons: London, UK, 2012.

34. Heiskanen, E.; Thidell, Å.; Rodhe, H. Educating sustainability change agents: The importance of practical skills and experience. J. Clean. Prod. 2016, 123, 218-226. [CrossRef]

35. Romano, N.C.; Nunamaker, J.F. Meeting analysis: Findings from research and practice. In Proceedings of the 34th Annual Hawaii International Conference on System Sciences, Maui, HI, USA, 3-6 January 2001; pp. 1-13.

36. Scott, S. Fierce Conversations: Achieving Success at Work E in Life, One Conversation at a Time; Penguin: New York, NY, USA, 2004.

37. Baugh, A. Stakeholder Engagement: The Game Changer for Program Management; CRC Press: Boca Raton, FL, USA, 2015; Volume 18.

38. Folke, C.; Carpenter, S.; Walker, B.; Scheffer, M.; Chapin, T.; Rockström, J. Resilience thinking: Integrating resilience, adaptability and transformability. Ecol. Soc. 2010, 15, 20. [CrossRef]

39. Arnstein, S.R. A ladder of citizen participation. J. Am. Inst. Plan. 1969, 35, 216-224. [CrossRef]

40. Cooke, B.; Kothari, U. Participation: The New Tyranny? Zed Books: London, UK, 2001.

41. Reed, M.; Evely, A.; Cundill, G.; Fazey, I.; Glass, J.; Laing, A.; Newig, J.; Parrish, B.; Prell, C.; Raymond, C.; et al. What is Social Learning? Available online: https://research-repository.st-andrews.ac.uk/bitstream/handle/ 10023/1624/Fazey2010EcologySociety15WhatIsSocialLearning.pdf?sequence=1\&isAllowed=y (accessed on 3 March 2017).

42. Leach, M.; Scoones, I.; Stirling, A. Dynamic Sustainabilities: Technology, Environment, Social Justice; Earthscan: London, UK, 2010.

43. Muff, K. (Ed.) The Collaboratory: A Co-Creative Stakeholder Engagement Process for Solving Complex Problems; Greenleaf Publishing: Saltaire, UK, 2014.

44. Knowles, M.S.; Elwood, F.H., III; Swanson, R.A. The Adult Learner: The Definitive Classic in Adult Education and Human Resource Development; Routledge: London, UK, 2007; pp. 132-139. 
45. Morgan-Klein, B.; Osborne, M. The Concepts and Practices of Lifelong Learning; Routledge: London, UK, 2007.

46. Dweck, C. Mindset: The New Psychology of Success; Penguin Random House: New York, NY, USA, 2006.

47. Sterling, S. Transformative Learning and Sustainability: Sketching the conceptual ground. Learn. Teach. High. Educ. 2010, 24, 17-33.

48. Tschakert, P.; Dietrich, K.A. Anticipatory learning for climate change adaptation and resilience. Ecol. Soc. 2010, 15, 11. [CrossRef]

49. Kolb, D.A. Experiential Learning: Experience as the Source of Learning and Development; FT Press: Upper Saddle River, NJ, USA, 2014.

50. Biggs, J. What the student does: Teaching for enhanced learning. J. High. Educ. Res. Dev. 1999, 18, 57-75. [CrossRef]

51. Wiggins, G.P.; McTighe, J. Understanding by Design. ASCD, 2005. Available online: http://www.ascd.org/ Default.aspx (accessed on 17 February 2017).

52. Brundiers, K.; Wiek, A.; Redman, C.L. Real-world learning opportunities in sustainability: From classroom into the real world. Int. J. Sustain. High. Educ. 2010, 11, 308-324. [CrossRef]

53. Wiek, A.; Xiong, A.; Brundiers, K.; Van Der Leeuw, S. Integrating problem- and project-based learning into sustainability programs. A case study on the School of Sustainability. Int. J. Sustain. High. Educ. 2014, 15, 431-449. [CrossRef]

54. Brundiers, K.; Wiek, A.; Kay, B.; Foucrier, T. Professional Skills in Sustainability. An Introduction to Communication, Teamwork, Project Management, Stakeholder Engagement, Self-Care, and Continuous Learning; School of Sustainability, Arizona State University: Tempe, AZ, USA, 2016.

55. Ganz, M.; Lin, E.S. Learning to lead: A pedagogy of practice. In Handbook for Teaching Leadership: Knowing, Doing, and Being; Snook, S., Nohria, N., Khurana, R., Eds.; SAGE: Los Angeles, CA, USA, 2011; pp. 353-366.

56. Kelan, E. Moving bodies and minds-The quest for embodiment in teaching and learning. High. Educ. Res. Netw. J. 2011, 3, 39-46.

57. Tippett, K. Better Conversations. A Starter Guide. 2016. Available online: http:/ /www.civilconversationsproject. org/centeringconversations/ (accessed on 17 February 2017).

58. Felder-Silverman Learning Style Index. Available online: http://www4.ncsu.edu/unity/lockers/users/f/ felder/public/ILSpage.html (accessed on 17 February 2017).

59. Ash, S.L.; Clayton, P.H. The articulated learning: An approach to guided reflection and assessment. Innov. High. Educ. 2004, 29, 137-154. [CrossRef]

60. Richards, C. Outcomes-based authentic learning, portfolio assessment, and a systems approach to 'Complex Problem-Solving': Related pillars for enhancing the innovative role of PBL in future higher education. J. Probl. Based Learn. High. Educ. 2015, 3, 78-95.

61. Clarke, J.L.; Boud, D. Refocusing portfolio assessment: Curating for feedback and portrayal. Innov. Educ. Teach. Int. 2016. [CrossRef]

62. Ryan, G.W.; Bernard, H.R. Data management and analysis methods. In Handbook of Qualitative Research, 2nd ed.; Denzin, N., Lincoln, Y., Eds.; Sage Publications: Thousand Oaks, CA, USA, 2000; pp. 769-802.

63. Lee, J.S.; Blackwell, S.; Drake, J.; Moran, K.A. Taking a leap of faith: Redefining teaching and learning in higher education through project-based learning. Interdiscip. J. Probl. Learn. 2014, 8, 3-13. [CrossRef]

64. Tucker, B. The flipped classroom. Educ. Next 2012, 12, 82-84.

65. McLaughlin, J.E.; Roth, M.T.; Glatt, D.M.; Gharkholonarehe, N.; Davidson, C.A.; Griffin, L.M.; Mumper, R.J. The flipped classroom: A course redesign to foster learning and engagement in a health professions school. Acad. Med. 2014, 89, 236-243. [CrossRef] [PubMed]

66. Center for Contemplative Mind in Society. Available online: http://www.contemplativemind.org/ (accessed on 17 February 2017).

67. Dam-Mieras, R.; Lansu, A.; Rieckmann, M.; Michelsen, G. Development of an Interdisciplinary, Intercultural Master's Program on Sustainability: Learning from the Richness of Diversity. Innov. High. Educ. 2007, 32, 251-264. [CrossRef]

68. Soares, L. Post-Traditional Learners and the Transformation of Postsecondary Education: A Manifesto for College Leaders. 2013. Available online: http:/ / www.acenet.edu/news-room/Documents/Post-TraditionalLearners.pdf (accessed on 17 February 2017). 
69. Willer, R. Can Empathy Bridge Political Divides? Interview with Alex Shashkevich. Available online: http://greatergood.berkeley.edu/article/item/can_empathy_bridge_political_divides (accessed on 17 February 2017).

70. Palmer, P. The Inner Life of Rebellion. Interview with Krista Tippett and Courtney Martin. Available online: http:/ / www.onbeing.org/ (accessed on 17 February 2017). 